\title{
BMJ Open Perspective of geriatric patients on advance care planning in Denmark: a qualitative study
}

\author{
Kirstine Dahmke, ${ }^{1}$ Elisabeth Nielsen-Hannerup, ${ }^{1}$ Ida Søndergaard Madsen, ${ }^{1}$ \\ Sofie Rerup, ${ }^{2}$ Emilie Ramberg, ${ }^{1}$ Maurice A Lembeck, ${ }^{1}$ Hanne Pedersen, ${ }^{3}$ \\ Ellen Astrid Holm (D) ${ }^{3,4}$
}

To cite: Dahmke K, NielsenHannerup E, Madsen IS, et al. Perspective of geriatric patients on advance care planning in Denmark: a qualitative study. BMJ Open 2022;12:e056115. doi:10.1136/ bmjopen-2021-056115

- Prepublication history for this paper is available online To view these files, please visit the journal online (http://dx.doi. org/10.1136/bmjopen-2021056115).

Received 04 August 2021 Accepted 11 February 2022

Check for updates

(C) Author(s) (or their employer(s)) 2022. Re-use permitted under CC BY-NC. No commercial re-use. See rights and permissions. Published by BMJ.

${ }^{1}$ Department of Internal Medicine, Nykøbing Falster Sygehus, Nykobing, Denmark

${ }^{2}$ Department of Social Medicine,

Frederiksberg Hospital,

Frederiksberg, Denmark

${ }^{3}$ Internal Medicine, Zealand

University Hospital Koge, Koge,

Denmark

${ }^{4}$ Institute of Clinical Medicine, University of Copenhagen, Kobenhavns, Denmark

Correspondence to

Dr Ellen Astrid Holm; ellh@regionsjaelland.dk

\section{ABSTRACT}

Objective Most previous studies on advance care planning (ACP) have focused on patients with specific diseases and only a few on frail ageing individuals. We therefore decided to examine the perspective of geriatric patients on ACP. Our research questions include if, when, with whom and with which content geriatric patients wish to have ACP conversations.

Design Participants were interviewed either in the hospital or in their own home. The interviewer followed a semistructured interview guide. Interviews were transcribed and analysed using the systemic text condensation method.

Setting Geriatric department in a regional hospital in a rural area in Region Zealand, Denmark.

Participants We included 11 geriatric patients aged above 65 who had been referred for geriatric inpatient or outpatient assessment. Participants were clinically judged by experienced geriatricians to have sufficient physical and mental capacity to take part in an interview.

Results This study's main finding is that geriatric patients have varying preferences and feelings towards ACP. Some expressed concerns about ACP, especially regarding personal fear to talk about end-of-life (EOL) decisions, and whether a busy healthcare system has the resources to conduct ACP. Proper timing of ACP seemed unrelated to specific age but related to perception of health situation. The health professional involved should be well trained and a person the participant could trust. Most participants wanted family members to participate. Concerning content, participants mentioned quality of life, fear of losing their spouse, earlier experience with death, and practical concerns regarding funeral and will.

Conclusion Among geriatric patients, feelings towards ACP are mixed. Even participants who were generally positive towards the concept uttered concerns about the circumstances when talking about EOL topics. Health professionals therefore should approach ACP discussions with caution. Further studies aiming to develop guidelines describing the proper way to introduce and perform ACP in this patient group are needed.

\section{INTRODUCTION}

Healthcare systems worldwide are facing a challenge due to an increasing ageing population. ${ }^{1}$ A proper healthcare for elderly and

\section{Strengths and limitations of this study}

- The method provides in-depth insight into a group of geriatric patients' attitudes towards advance care planning (ACP).

- Participants were interviewed in a stable phase, and attitudes in an acute phase have not been examined.

- The qualitative method limits results to being an insight into geriatric patients' attitudes to ACP in a Danish context.

their age-related diseases must be ensured to secure their well-being as a human right. ${ }^{2}$ Advance care planning (ACP) is a method to explore and follow individual goals, values, treatment planning and care in the last phase of life. A multidisciplinary team of experts from around the world agreed on the following definition of $\mathrm{ACP}^{3}$ :

Advance care planning enables individuals to define goals and preferences for future medical treatment and care, to discuss these goals and preferences with family and health-care providers, and to record and review these preferences if appropriate.

The effects of ACP have been studied in several settings. ACPs have a clearly beneficial effect on the quality of end-of-life (EOL) care. ${ }^{4}$ ACP programmes containing multiple conversations are more effective than a simple ACP tick-box document and result in higher compliance with EOL treatment. ${ }^{56}$ Higher patient satisfaction regarding treatment and care has been observed after ACP conversations. ${ }^{4-8}$ ACP reduces the amount of days spent in the hospital ${ }^{9} 10$ and increases the likelihood of compliance with the patient's preferred place of death in studies including patients with pulmonary diseases, heart diseases or cancer. ${ }^{9}$ 
The patient's relatives have an important impact on the ACP. Family attendance during ACP conversations raised the tendency for the patient to participate and to select a next of kin to make decisions on their behalf. ${ }^{6}$ ACP may help relatives and healthcare professionals achieve a better understanding and acceptance of the patient's wishes concerning $\mathrm{EOL}^{11}$ and may result in less stress, anxiety and depression among the relatives after the death of their beloved one. ${ }^{6}$

Among patients who have participated in ACP conversations, fewer wish resuscitation; fewer are in doubt about their wishes; and their wishes have been documented more frequently. ${ }^{11}$

Furthermore, studies have indicated that ACP could be economically beneficial. However, this depends on the type of ACP intervention as well as the structure of the healthcare system. ${ }^{12}$

However, studies have also observed uncertainties and barriers. Fear of future illness is a barrier for participation in an ACP conversation. Additionally, relatives' reluctance to talk about EOL and a passive expectation that others will make decisions on behalf of the patient may be a barrier to engaging in an ACP conversation. ${ }^{13}$ Timing of ACP is crucial. Patients may fear that ACP is conducted too late ${ }^{13}$ and studies suggest that it may be too late to introduce ACP to severely ill patients. ${ }^{11}$

The majority of studies concerning ACP have included patients with specific diseases like pulmonary or cancer diseases. Only a few have focused on frail geriatric patients with multimorbidity. ${ }^{6-13}$ However, the group of frail geriatric patients is the single largest group including almost half of all decedents. The last period of their lives is characterised by a slow decline with progressive disability before dying from complications associated with frailty, for example, stroke or dementia. Lunney et al categorised 7966 older Medicare decedents into four profiles: frailty, cancer, sudden death, or organ failure. Frailty turned out to be the dominant profile including $47 \%$ of all decedents, whereas cancer could explain death in $22 \%$. ${ }^{19}$ The lack of ACP conversations in the group of frail elderly persons may contribute to overtreatment and possibly futile tests and procedures in this group of patients. Receiving a cancer diagnosis or a diagnosis of specific organ failure may be an event that triggers a discussion on prognosis between patient, family and healthcare professionals. However, frailty is a syndrome developing gradually, and it is not clear at what point frailty should trigger a similar discussion. This may be the reason for the very few studies concerning ACP in this patient group.

A review from 2017 focused on attitudes towards ACP in frail geriatric patients and concluded 'one of the study's main findings was the paucity of studies specifically involving these populations'. ${ }^{13}$

The focus of the present study is geriatric patients referred to an inpatient or an outpatient geriatric clinic. Geriatric patients generally have elements associated with frailty such as cognitive dysfunction, falls, gait instability or need of assistance in basic activities of daily living.

\section{Aim}

The aim of this study was to examine attitudes of geriatric patients concerning ACP. Our research questions include if, when, with whom and with which content geriatric patients wish to have ACP conversations. The interview guide shows in more detail how these questions were addressed (see table 1).

\section{METHODS}

This study applied the Consolidated Criteria for Reporting Qualitative Research. ${ }^{20}$

\section{Design and data collection}

The study was based on individual semistructured interviews. An interview guide was developed by EN-H and ISM based on existing knowledge concerning ACP in this patient group. ${ }^{6}{ }^{13-18}$ All interviews were performed by author EN-H. Ideally, we aimed to have an interviewer and an observer for all interviews, but for logistic reasons partly due to the COVID-19 pandemic, some interviews were performed by EN-H alone. EAH participated as observer in one interview, $\mathrm{KD}$ in one and $\mathrm{SR}$ in three. EN-H was the main interviewer in all interviews and the observer was allowed to pose further questions. The interviewer and the observers did not undergo any specific training in interview technique but were all trained in interviewing patients as part of their medical training. After oral consent, participants got a short written document containing the study's purpose, expected topics of conversatio and the research department's contact information.

\section{Sample size}

We used convenience sampling and aimed to include approximately 10 geriatric patients. Since the purpose of the study was to gain insight into geriatric patients' perspective, rather than a complete coverage of themes, thematic saturation was not considered a goal. ${ }^{21}$ We aimed for 10 participants because we wanted to perform in-depth interviews and we considered 10 to be enough to supply us with a sufficiently rich and heterogeneous data material.

\section{Participants and setting}

The only criteria for inclusion were that participants should fall within the definition of being geriatric patients as defined by Union Européenne des Médecins Spécialistes as part of the definition of geriatric medicine:

This group of patients are considered to have a high degree of frailty and active multiple pathology, requiring a holistic approach. Diseases may present differently in old age, are often very difficult to diagnose, the response to treatment is often delayed and there is frequently a need for social support. Geriatric Medicine therefore exceeds organ orientated medicine offering additional therapy in a multidisciplinary team setting, the main aim of which is to optimize the 
Table 1 Interview guide

Introduction Can you tell us a bit about yourself?

\section{Thematic questions}

Knowledge and attitudes concerning own health/diseases

How are the patients' perception and knowledge of their prognosis?

\section{General thoughts}

What considerations have geriatric patients made about the last stage of life?

\section{Dynamic questions}

Hopes?

Expectations? Concerns?

What thoughts do you have regarding your health?

What thoughts have you had about the future development of your health?

Have you talked to your doctor about potential future health issues?

In case of disease, would you like to know the prognosis?

Did you discuss with your doctor whether the medication you are taking is a lifelong treatment?

What thoughts have you had about what is important for you in the last stage of your life?

- Have you considered what would be important to you in the course of a disease if you were to become seriously ill?

- Have you talked to your relatives about what is important to you if you became ill?

If yes, how have you talked about it?

If not, why have you not talked about it? Is it something you would consider talking to your relatives about?

- Have you talked to your relatives about what kind of treatment you would want or not want if you would become seriously ill in the future?

If yes, who started the conversation and what did you talk about?

Do you know what the concepts of living will or advanced directives mean?

If yes, have you made one? Why/why not?

If not, would you like to make one? Why/why not?

- Have you chosen someone who can make decisions for you should you be incapable of doing so? If yes, who and why? If not, would you like to choose one? Why/why not?

Need

How is the need for conversations about met? the last stage of life and is this need

Have you previously talked to a healthcare professional about the last stage of life? Have you been offered to do so?

- Would you like to talk to a healthcare professional about it? Why/why not?

- Have you expressed an interest in such a conversation but have been rejected?

Scenarios.

Imagine that you have just been hospitalised. A nurse asks you about your wishes for treatment and care in case of future incapacity. What would your thoughts be?

What would you think about your GP asking you if you had thought about your wishes for treatment and care in case of future incapacity?

\section{Framework \\ How is a good setting created for a conversation about the last stage of life?}

\section{Content}

What should a conversation about the last stage of life include?

- In a conversation about the last stage of life, what do you find important to talk about?

What aspects of the last stage of life would you like to talk to a healthcare professional about?

Are there any topics you would not want to talk about?

Which healthcare professional would you like to talk to about it? Why? Scenario: hospital doctor, nurse or GP?

In your opinion, who should initiate the conversation?

Where would you prefer for a conversation about the last stage of life would take place?

When and how often could you imagine having such a conversation? What are your thoughts on being routinely offered such a conversation when hospitalised?

Would you like to have your relatives with you for such a conversation? If yes, who? Why? If not, why not?

Communication

What is the experience of how healthcare professionals communicate difficult topics such as death and the level of treatment?
- Have you ever had a conversation with a healthcare professional about a difficult topic, for example, death or loss? If so, can you describe the conversation and what you gained from the conversation?

What do you think makes such a conversation constructive and meaningful? What contributes to the contrary?

Is there something the healthcare professional can do to make the conversation good or bad?

Is there something that can make a conversation about the last phase of life easy or difficult?

GP, general practitioner.

functional status of the older person and improve the quality of life and autonomy. ${ }^{22}$

In the present study, we included patients above the age of 65 who had been referred for geriatric out-patient assessment by their general practitioner (GP) or who had been acutely admitted to a geriatric ward. Furthermore, they should be in a cognitive and physical state, which made it possible for them to participate in the interview. The physical and cognitive ability of participants relied on a clinical judgement by either of two experienced geriatricians (EAH or MAL). We recruited participants in the geriatric outpatient clinic as well as in the geriatric inpatient department. If participants gave consent to take part, they were contacted by EN-H, who made a specific appointment concerning the time and place for the interview. The participants could choose whether they wanted the interview to take place in the geriatric department or in their own home. If a participant preferred to have the 
interview in the hospital, the interview was performed in the outpatient clinic in a quiet consultation room where only the participant and the interviewer were present.

\section{Transcription and analysis}

The interview guide was written in Danish and interviews were performed in Danish. All text analysis was performed in Danish. For the sake of the present article, the interview guide and all patients' quotes were translated into English. EN-H and ISM performed translation of the interview guide, and $\mathrm{KD}$ and $\mathrm{EAH}$ translated patients' quotes cited in the article. Interviews were taped and transcribed by authors $\mathrm{KD}$ and $\mathrm{EN}-\mathrm{H}$ using the software system NVivo V.12. The coding and subsequent content analysis followed the four steps in systematic text condensation as described by Malterud. ${ }^{23}$ Systematic text condensation is an inductive content analysis where the themes are derived from the data. It constitutes a well-described practical method, which can be used to analyse text material in a systematic and transparent way. It secures transferability of the findings without claiming saturation. ${ }^{23}$

The first step is to read all the transcripts, where the overall impression of the content is explored. The second step is to identify and code the transcribed material for typically three to five main themes. The third step is to identify meaningful units from which condensates are formulated. Finally, the condensates are replaced by characteristic citations from the transcribed material in order to let the participants' voices express the meaningful content. KD and EN-H performed all coding tasks, and in case of disagreement, EAH was involved and settled the question. To validate the results, two authors (HP and SR) finally read the transcribed interviews and the results to catch possible misunderstandings or missing themes.

\section{Patient and public involvement}

Patients and public were not involved in the development of this study.

\section{RESULTS}

We aimed to include approximately 10 geriatric patients; however, a spouse to one of the patients asked if she could be interviewed as well, and since she fulfilled the criteria of being a geriatric patient, we ended up interviewing 11 participants.

Participants in the inpatient department turned out to be suffering from acute conditions and were often not able to take part in a decision concerning participation. Only two participants were recruited during in-hospital stay. Nine participants (including a spouse) were recruited from the geriatric outpatients clinic. Nine participants were interviewed in their own homes and two in the hospital.

Six participants had been referred to the geriatric outpatient clinic for falls and balance problems and two for minimal cognitive decline. The spouse of one of these had depression, anxiety and cardiac disease. Two

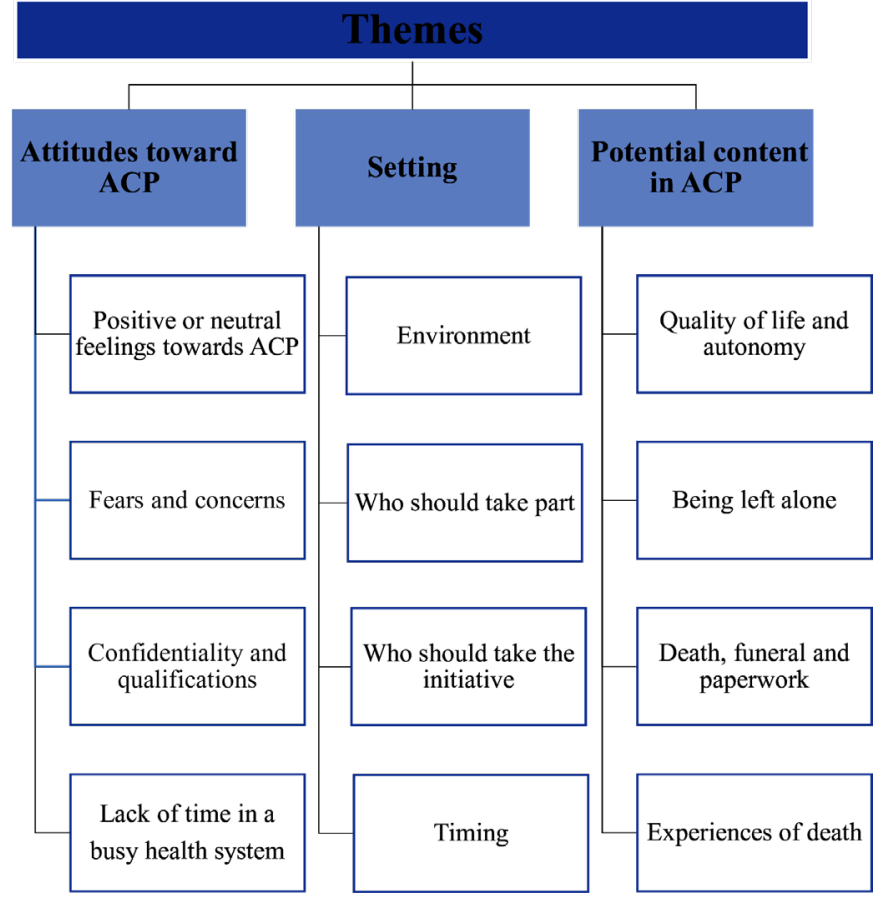

Figure 1 Illustration of the overall themes arising from the interviews. ACP, advance care planning.

inpatients were admitted due to pneumonia, and both had multiple medical problems and loss of basic activity of daily living functions as well. Participants had a mean age of 82, range 67-93. Interviews lasted between 73 and $127 \mathrm{~min}$. The validation process showed that the results as described further did not miss essential themes. Figure 1 shows the overall themes reported in detail as follows.

\section{Attitudes toward ACP conversation}

Positive or neutral feelings concerning ACP conversations

Some felt attracted to the idea of having an ACP conversation:

That sounds very reasonable. Because you have surrendered those opinions while you were clearheaded. I think that makes very good sense. (Man, 73 years)

Some told that they had never discussed EOL issues not because they were scared or felt uncomfortable with the discussion but because they did not feel a need.

... I do not mind talking about it [the time left]. It is just not something we have discussed. Well, we are not 80 years old yet. Only seventy years. [laughs] [Man, 67 years]

I may go to bed tonight, perhaps, and not wake up in the morning. I do not know. I cannot say that until I wake up. There is nothing else to do, as one says, take it one day at a time and then see what happens the next day, right? (Man, 67 years)

I look forward to the future. Maybe that is also, why I have not thought so much about what I really need at that time. We take one day at a time. (Man, 73 years) 
During some of the interviews, it was clear that the interview itself stimulated new thoughts in the participants who started thinking about the advantages of discussing EOL wishes with close relatives. One participant started very concrete planning:

Then I would invite them [his children] home for a meal, right? Then we can sit quietly and talk about it if they want to be part of it of cause. [...] maybe next month. (Man, 67 years)

\section{Fears and concerns}

Some participants clearly expressed that they did not like talking about death or discussing EOL issues.

I must admit that I am a chicken with something like that, so I would, if I could, then I would probably push it away from me. (Man, 73 years)

One participant described a fear of ending life prematurely due to what he might have told a doctor about his wishes concerning treatment in certain situations.

I am a little scared to give the doctor too much information. Many times, it does not take much before they react in some way. (Man, 86 years)

\section{Confidentiality and qualifications}

Some expressed concerns about having to share personal thoughts with an unknown physician.

... maybe it is not a person who knows me, and I do not know him. [...] maybe one of mine should participate $[\ldots]$ one or more of my family members $[\ldots]$ one who could see the human dimension of the matter. (Man, 82 years)

Some worried whether the health professional who would take part was competent.

It should not be someone, who is early in their education. It should preferably be one where you know the doctor is qualified. (Man, 73 years)

One participant recalled a previous experience where a physician failed to create the right atmosphere and trust from the beginning of the conversation, due to focusing on the computer rather than having eye contact with the patient.

[...] how can you behave like that when you meet a patient? Well, the first thing must be like saying hello, so you introduce yourself, [...] (Man, 82 years)

\section{Lack of time in a busy healthcare system}

Some were concerned whether the doctor and hospital staff would be too busy.

I have to say, it is perhaps a little worrying, how, how overloaded the hospital staff is, right? Do they have the necessary time for something like that? (Man, 82) A par
GP.

A participant shared her fear of being a burden to her

I know how much time pressure those doctors have $[\ldots]$. They do not have much time, so if I [...] were to talk about this, then I should have extra time. (Woman, 76 years)

\section{Setting \\ Environment}

Concerning the environment where an ACP conversation should take place, the participants expressed thoughts about the right atmosphere.

Well, it must be in a room that is relaxed to be in, not a small sterile place. I think it is nice that you are here in my home, but it could very well be somewhere else. However, it should be in a somehow cosy room. Where one does not sit on a rigid chair or such. Maybe with a flower on the table, I am not sure. (Woman, 76 years)

\section{Who should take part in an ACP conversation?}

Some felt that thoughts regarding wishes for treatment or no treatment during the EOL phase and concerning death and burial were intimate and should be shared only with close relatives.

I think it is something the doctor has nothing to do with. [...] It is something that you talk about, for me, it will be with [name of wife] and if I wanted any further, then I will talk to [name of son] about it. [...] I would never start talking with the neighbour about it... (Man, 86 years)

I would be one hundred percent sure that she [wife] will make the right decision. You do not live together for over 60 years without getting to know each other. $[\ldots]$ it gives one some peace of mind to know that there is a person that you can count on 100 percent in all directions. (Man, 86 years)

Regarding participation of health professionals, the participants expressed the need for trust, personal qualities such as empathy, and training of the health professional.

You must have a relationship of trust with your doctor [...] I do not have the same trust in my new doctor, because I do not know him very well. (Man, 82 years)

Maybe it should be a doctor, but then again, a nurse could also do it. It could be both, I think. (Woman, 76 years)

Maybe because you have the impression that female doctors have a little more empathy, I do not know, but I could imagine. (Man, 73 years)

Generally, the participants found that relatives should take part. 
I would not mind if XX [wife] was with me. [...] we would be two to remember what was said. (Man, 73 years)

However, some participants preferred to be alone. One participant suspected that the health professionals would talk to her relatives instead of talking to her.

They have offered it to both XX [son] and my daughter-in-law [...] I feel like it is them they are talking to and not me. [...] I said to them, "I can do it myself". (Woman, 91 years)

Another participant preferred to have the conversation alone:

I do not need someone to look after me. (Man, 93 years)

\section{Initiative for the ACP conversation}

Some felt that a health professional should initiate and lead the conversation. One of the informants described his expectation that the doctor would use his communication experiences to guide and navigate the conversion.

It makes a lot of sense if the doctor has some guiding questions [...] I think it would probably be nice if the doctor, based on the experience that a doctor has, would say "have you thought about this and that". (Man, 73 years)

However, for some, it might also be anxiety provoking if a doctor would start such a conversation.

Well, I am, maybe it is because I do not think I need one. That must be it. Because if the doctor calls me now, or says to me, "Shouldn't we have such a conversation about it," then I would believe the doctor might have something to tell me. Not just that there was something she or he was open for me to tell. (Man, 73 years)

If more than once was needed, the patient should take the initiative.

Well, then you can say that you yourself have to reach out and say, "Well now, I had this opinion then, now I have a new one", right? But it should be my initiative. (Man, 82 years)

\section{Timing}

The participants were asked about the proper timing to conduct the ACP conversation. No comments pointed to a specific age at which an ACP conversation should be offered. However, readiness is an issue as expressed in the following by a woman who had been asked a couple of years ago about her wish concerning resuscitation when she had just undergone surgery.

But I was not at all prepared to talk about it [then]. It is okay to ask me today. Today I can see that something can happen [...] I would not deny a conversation in the same way now, as I did back then. (Woman, 91 years)

\section{Potential content in ACP conversations}

When we asked participants what they would find important to discuss in an ACP conversation, they mentioned several issues as relevant concerning their wishes for the last period of their life. Further, we summarise the themes that came up in this category.

\section{Quality of life and autonomy}

An important theme was the wish to be able to do the things you like and not being dependent on others. Some participants referred to family, neighbours, or friends whom they pitied.

My good neighbour over there, who is 10 years younger $[\ldots]$ got a heart attack and was flown to the national hospital, and they saved his life." But what a life $[\ldots]$ " he says. (Man, 93 years)

[...] my son-in-law has a brother who for 18 years has been eating food from a stomach tube because he has had cancer [...] I could not imagine that. Life must be lived [...] Life should not just be being kept alive. Because it is just a postponement of death. (Man, 93 years)

I have to say if it is a stroke and it is something serious, then I would rather be allowed to die. (Man, 76 years)

The possibility of having to move into a nursing home was frightening to some.

Many of the people I talk about have been in nursing homes $[\ldots]$. If the head does not function, then I would prefer to be completely gone [...]. I have experienced so many who have sat like this, and I think it is awful [...]. I do not think my family should be subject to that $[\ldots]$. I do not want to end life that way. (Woman, 91 years)

\section{Being left alone}

Participants living with a spouse considered their marriage and their reliance on their partner to be an important fact that they would take into consideration as part of the content in an ACP conversation.

I might get some mental problems [if his wife dies before him]. I am not very good at being alone [...] hopefully I am the one to be dead and buried first. (Man, 86 years)

If I have my wife, then I am not so sad [...]. However, if I do not have her, I probably think I will go to a nursing home or retirement home or whatever you call it. [if dementia]. (Man, 67 years)

\section{Death, funeral and paperwork}

Participants spontaneously shared detailed thoughts and considerations regarding making a will and how they wanted the ceremony and memorial service to be. 
I do not want to be put down in the cold ground. I want to be burned. And we agreed [his wife and him] on that a long time ago, that is the way things are. (Man, 75 years)

No coffee drinking! I hate it when you sit there and weep $[\ldots]$ the coffin must be left in the church, where it is nicely decorated with flowers and such. [Man, 86 years]

\section{Experiences of death}

Participants mentioned experiences with the death of others when explaining their own attitudes.

XX (husband) had a father who had Parkinson's disease [...] He could do nothing, but his head was clear. $[\ldots]$ we said at the nursing home that if he gets a cardiac arrest, then you should not start it again. $[\ldots]$ it is good that you can say to your doctor, "I do not want that". (Woman, 76 years)

One participant told how an aunt had wished not to have her life prolonged. However, her wish was not respected and 'she had tubes put into her'. This experience had informed a discussion between her and her husband.

If we become very seriously ill and someone in the hospital wants to try to prolong life by different actions, then we would like to be able to say no. (Woman, 76 years)

Some also told about experiences of regretting not having talked with their loved ones about dying.

I now know that my husband clearly had thoughts about dying. However, I have pushed them away from me. [...] And I regret it, or rather, today I am sorry. (Woman, 91 years)

Another participant told about the death of his mother.

[...] we did not talk about it, we did not. She then wrote a letter to us kids afterwards that she had had a good life and stuff like that, but while it was going on, we pretty much did not talk about it. And I do not know if it might have been good. (Man, 73 years)

\section{DISCUSSION}

\section{Main findings}

This study's main finding is that geriatric patients have varying preferences and feelings concerning ACP. Some expressed concerns about ACP, especially regarding personal fear to talk about EOL decisions, and whether a busy healthcare system has the resources to conduct ACP. However, an easiness was observed for participants to talk about ACP-relevant topics during the interview, where especially experiences with death of relatives raised thoughts about their own preferences for EOL.

\section{Attitudes toward ACP}

Attitudes were very mixed with some participants being positive towards the ACP concept but also expressing ambivalence about participating in an ACP conversation. Some did not mind a conversation but did not feel a need for a conversation. A majority would agree to participate in a conversation if offered, but some found it unpleasant to talk about death or discussing EOL issues, and one participant explicitly stated that he would decline an ACP conversation.

A similar discrepancy was shown by Musa $e t a l^{24}$ when they demonstrated that out of those participants who had a positive attitude towards an ACP interview, only $17 \%$ had actually participated in an ACP interview. One of our participants expressed fear anticipating a potential stop of the treatment due to an ACP discussion. Similarly, Musa et al found that $35 \%$ of the participants worried that their life could be ended prematurely due to ACP. ${ }^{24}$

Some of our participants found it depressing to talk about the EOL and wanted to postpone such discussions until later. Similarly, Hanson et $a l^{25}$ reported that some participants found that an EOL conversation could give rise to anxiety and depressive thoughts.

A greater readiness for ACP was observed in those who had previous experiences with EOL care concerning relatives or friends. This was also shown by Amjad et al. ${ }^{26}$

\section{Setting}

There were varying opinions among the participants regarding who should start the conversation about ACP. Some found it anxiety provoking without preparation to be asked about the need for ACP, while others found it sensible if a physician would guide the patient through an ACP interview. Previous studies ${ }^{27-29}$ show a similar desire among patients that the doctor should take the initiative to talk about resuscitation, which may be a subtopic of ACP. However, the approach from a health professional concerning resuscitation should be cautious. ${ }^{25}$

The timing of an ACP conversation was difficult for the participants to define. However, the participants pointed out that they need to feel a readiness to talk about EOL. Being ready is not referred to as a specific age but rather an individual development, which may be dependent on life events and experiences. A proper readiness has also been mentioned in a systematic review by Sellars $e t a l,{ }^{30}$ in which patients with dementia and their carers described a fear of talking about disease progression in advance. The study mentioned a desire to postpone conversation until it was necessary. However, carers also described a regret for not having held ACP while a demented relative still had enough clarity to participate in the conversation.

McMahan $e t a l^{31}$ described a greater involvement of ACP in patients with depression and anxiety and decreased appreciation of life-prolonging treatment. Both aforementioned studies indicate that the right timing likely is more about readiness and experiences than a specific age. 
Some of our participants found that conversations about EOL were intimate and should be shared only with close relatives. Similar attitudes were shown in other studies. ${ }^{2432}$ However, a study by Gessert $e t a l^{33}$ about family members' decisions for EOL of institutionalised patients with dementia showed, that family members felt great discomfort in having to decide EOL treatment. Therefore, a conflict may occur between patients' and their relatives' wishes. Other studies ${ }^{34-36}$ have described an important active role of carers, especially when overcoming barriers to participation in ACP. However, Sharp et $a l^{13}$ found that family members could be reluctant to talk about EOL due to a lack of acceptance of the situation.

\section{Content}

Quality of life was a dominating theme. Many feared not being able to take care of themselves. This fear was linked to experiences with family members, friends or neighbours. Participants described experiences providing insight into their pity and an indirect expression of a perception of an unworthy life as a consequence of autonomy loss. This fear of illness and the need for care was also expressed when talking about nursing homes, where many of the participants described experiences from TV broadcasts and acquaintances who had experienced poor care conditions and lack of quality of life. This view also appeared in a study by Pleschberger, ${ }^{37}$ in which the participants mentioned inadequate care in nursing homes, a desire to be active to the last and a desire to 'be allowed to die'. A recent study ${ }^{25}$ mentions the same fear of lack of autonomy and dignity in nursing homes, and it is further pointed out that moving to a nursing home is associated with fear: 'if you are not already crazy, then you will be'.

\section{Strengths and limitations}

The qualitative method used in this study provides in-depth insight into the attitudes of geriatric patients towards ACP discussion. The text analysis method used is well described in the research literature and ensures that findings to some extent can be generalised. However, attitudes may be dependent on culture and on the patients' own situation. We therefore suggest that our results should be interpreted as findings concerning attitudes among stable geriatric patients in Denmark.

\section{CONCLUSION}

The results of this study demonstrate mixed attitudes towards ACP among the geriatric participants. Some participants uttered concerns about the circumstances when talking about EOL topics. Health professionals therefore should approach an ACP discussion with caution. Future studies are needed to further understand geriatric patients' needs and concerns for ACP, and further examination of the best way to introduce ACP to patients is needed.

\section{Implications for future research}

We found a rather scarce amount of studies concerning attitudes towards ACP conversations among frail elderly patients. Our findings, combined with the findings from the literature concerning attitudes towards ACP discussions in this population, can be used to plan future randomised studies comparing different models of ACP and their effect in real life. Qualitative studies experimenting with different ways of approaching frail geriatric patients and their families in different settings, as well as quantitative randomised controlled studies concerning outcomes such as quality of life and perceived quality of care, are needed.

Contributors KD, EN-H, ISM and EAH planned the study. ER, MAL and EAH were involved in recruiting the participants. $\mathrm{EN}-\mathrm{H}, \mathrm{KD}, \mathrm{SR}$ and $\mathrm{EAH}$ collected the data. $\mathrm{KD}$ and $\mathrm{EN}-\mathrm{H}$ transcribed the interviews. KD, EN-H and EAH were involved in the text analysis. HP and SR validated the analysis. All authors took part in discussions of results during the process of analysis and discussions concerning the final manuscript. KD produced the first draft of the article. All authors approved the final manuscript. EAH act as guarantor.

Funding The authors have not declared a specific grant for this research from any funding agency in the public, commercial or not-for-profit sectors.

Competing interests None declared.

Patient and public involvement Patients and/or the public were not involved in the design, conduct, reporting or dissemination plans of this research.

Patient consent for publication Not applicable.

Ethics approval This study involves human participants, but Danish law exempts this type of survey study from ethical approval. Participants gave oral consent and were informed that they could withdraw consent at any time. The project was reported to the regional ethical committee and registered as case number EMN-2020-36198.

Provenance and peer review Not commissioned; externally peer reviewed.

Data availability statement No data are available. Patients or the public were not involved in the design, or conduct, or reporting, or dissemination plans of our research.

Open access This is an open access article distributed in accordance with the Creative Commons Attribution Non Commercial (CC BY-NC 4.0) license, which permits others to distribute, remix, adapt, build upon this work non-commercially, and license their derivative works on different terms, provided the original work is properly cited, appropriate credit is given, any changes made indicated, and the use is non-commercial. See: http://creativecommons.org/licenses/by-nc/4.0/.

ORCID iD

Ellen Astrid Holm http://orcid.org/0000-0002-7600-6025

\section{REFERENCES}

1 World Health Organization. Ageing and health, 2021. Available: https://www.who.int/news-room/fact-sheets/detail/ageing-andhealth [Accessed 12 Dec 2021].

2 United Nations, Human Rights, Office of the High Commissioner. Human rights of older persons, 2021. Available: https://www. ohchr.org/en/issues/olderpersons/pages/olderpersonsindex.aspx [Accessed 12 Dec 2021].

3 Rietjens JAC, Sudore RL, Connolly M, et al. Definition and recommendations for advance care planning: an international consensus supported by the European association for palliative care. Lancet Oncol 2017;18:e543-51.

4 Brinkman-Stoppelenburg A, Rietjens JAC, van der Heide A. The effects of advance care planning on end-of-life care: a systematic review. Palliat Med 2014;28:1000-25.

5 Houben CHM, Spruit MA, Groenen MTJ, et al. Efficacy of advance care planning: a systematic review and meta-analysis. J Am Med Dir Assoc 2014;15:477-89. 
6 Detering KM, Hancock AD, Reade MC, et al. The impact of advance care planning on end of life care in elderly patients: randomised controlled trial. BMJ 2010;340:c1345.

7 Wright AA, Zhang B, Ray A, et al. Associations between end-of-life discussions, patient mental health, medical care near death, and caregiver bereavement adjustment. JAMA 2008;300:1665-73.

8 Tierney WM, Dexter PR, Gramelspacher GP, et al. The effect of discussions about advance directives on patients' satisfaction with primary care. J Gen Intern Med 2001;16:32-40.

9 Skorstengaard $\mathrm{MH}$, Jensen $\mathrm{AB}$, Andreassen $\mathrm{P}$, et al. Advance care planning and place of death, hospitalisation and actual place of death in lung, heart and cancer disease: a randomised controlled trial. BMJ Support Palliat Care 2020;10:e37.

10 Martin RS, Hayes B, Gregorevic K, et al. The effects of advance care planning interventions on nursing home residents: a systematic review. J Am Med Dir Assoc 2016;17:284-93.

11 Krones T, Budilivschi A, Karzig I, et al. Advance care planning for the severely ill in the hospital: a randomized trial. BMJ Support Palliat Care 2019. doi:10.1136/bmjspcare-2017-001489. [Epub ahead of print: 21 Jan 2019].

12 Klingler C, in der Schmitten J, Marckmann G. Does facilitated advance care planning reduce the costs of care near the end of life? systematic review and ethical considerations. Palliat Med 2016;30:423-33.

13 Sharp T, Moran E, Kuhn I, et al. Do the elderly have a voice? advance care planning discussions with frail and older individuals: a systematic literature review and narrative synthesis. British Journal of General Practice 2013;63:e657-68.

14 Friis $\mathrm{P}$, Førde R. Forhåndssamtaler Med geriatriske pasienter. Tidsskrift for Den norske legeforening 2015;135:233-5.

15 Mueller PS, Hook CC, Fleming KC. Ethical issues in geriatrics: a guide for clinicians. Mayo Clin Proc 2004;79:554-62.

16 Overbeek A, Korfage IJ, Jabbarian LJ, et al. Advance care planning in frail older adults: a cluster randomized controlled trial. J Am Geriatr Soc 2018;66:1089-95.

17 Mignani V, Ingravallo F, Mariani E, et al. Perspectives of older people living in long-term care facilities and of their family members toward advance care planning discussions: a systematic review and thematic synthesis. Clin Interv Aging 2017;12:475-84.

18 Overbeek A, Korfage IJ, Hammes BJ, et al. Experiences with and outcomes of advance care planning in bereaved relatives of frail older patients: a mixed methods study. Age Ageing 2019;48:299-306.

19 Lunney JR, Lynn J, Hogan C. Profiles of older Medicare decedents. J Am Geriatr Soc 2002;50:1108-12.

20 Tong A, Sainsbury P, Craig J. Consolidated criteria for reporting qualitative research (COREQ): a 32-item checklist for interviews and focus groups. Int J Qual Health Care 2007;19:349-57.
21 Malterud K, Siersma VD, Guassora AD. Sample size in qualitative interview studies: guided by information power. Qual Health Res 2016;26:1753-60.

22 Definition of geriatrics. Available: https://uemsgeriatricmedicine.org/ www/land/definition/english.asp [Accessed 12 Dec 2021].

23 Malterud K. Systematic text condensation: a strategy for qualitative analysis. Scand J Public Health 2012;40:795-805.

24 Musa I, Seymour J, Narayanasamy MJ, et al. A survey of older peoples' attitudes towards advance care planning. Age Ageing 2015;44:371-6.

25 Hanson S, Brabrand M, Lassen AT, et al. What matters at the end of life: a qualitative study of older peoples perspectives in southern Denmark. Gerontol Geriatr Med 2019;5:233372141983019.

26 Amjad H, Towle V, Fried T. Association of experience with illness and end-of-life care with advance care planning in older adults. J Am Geriatr Soc 2014;62:1304-9.

27 Laakkonen M-L, Pitkala KH, Strandberg TE, et al. Older people's reasoning for resuscitation preferences and their role in the decisionmaking process. Resuscitation 2005;65:165-71.

28 Agård A, Hermerén G, Herlitz J. Should cardiopulmonary resuscitation be performed on patients with heart failure? the role of the patient in the decision-making process. J Intern Med 2000;248:279-86.

29 Morgan R, King D, Prajapati C, et al. Views of elderly patients and their relatives on cardiopulmonary resuscitation. BMJ 1994;308:1677-8.

30 Sellars M, Chung O, Nolte L, et al. Perspectives of people with dementia and carers on advance care planning and end-of-life care: a systematic review and thematic synthesis of qualitative studies. Palliat Med 2019;33:274-90.

31 McMahan RD, Barnes DE, Ritchie CS, et al. Anxious, depressed, and planning for the future: advance care planning in diverse older adults. $J$ Am Geriatr Soc 2020;68:2638-42.

32 Schiff R, Rajkumar C, Bulpitt C. Views of elderly people on living wills: interview study. BMJ 2000;320:1640-1.

33 Gessert CE, Forbes S, Bern-Klug M. Planning end-of-life care for patients with dementia: roles of families and health professionals. Omega 2000;42:273-91.

34 Fried T, Zenoni M, lannone L. A Dyadic perspective on engagement in advance care planning. J Am Geriatr Soc 2017;65:172-8.

35 Lum HD, Jordan SR, Brungardt A, et al. Framing advance care planning in Parkinson disease: patient and care partner perspectives. Neurology 2019;92:e2571-9.

36 Ho GWK, Skaggs L, Yenokyan G, et al. Patient and caregiver characteristics related to completion of advance directives in terminally ill patients. Palliat Support Care 2017;15:12-19.

37 Pleschberger S. Dignity and the challenge of dying in nursing homes: the residents' view. Age Ageing 2007;36:197-202. 